\title{
The psychological philosophy behind public baths in Indus Valley Civilisation
}

\author{
Akshyata Ray
}

Department of Psychology, Doon University, Dehradun, India

\begin{abstract}
Historically, public baths have been an integral part of all ancient civilisations. When talking about Indus Valley Civilisation, it is considered one of the oldest civilisation pertaining to mankind. While there is still a huge discrepancy related to the actual dates of the existence of this civilisation, the approximate span of this civilisation is taken as 2500-1700 B.C., as per carbon dating technique. The public baths were a common feature of Indus Valley civilisation, excavated at Mohenjodaro present in Pakistan and this paper presents a psychological perspective pertaining to these structures. Humans have a tendency to have stringent notions above their body and it has been found to be a cause of various psychological issues. This paper presents the view that our ancient civilisations paid special attention to the psychological wellbeing of individuals and had built the concept of public bath in order to instil a sense of love and ease related to their bodies.
\end{abstract}

Keywords - body image, Indus Valley Civilisation, psychological philosophy, psychological well being, public bath.

\section{INTRODUCTION}

Our ancient civilisations have been instilled with exemplary prowess in the field of science and engineering. Instances can be seen in various ancient civilisations be it the Egyptian civilisation or Mesopotamian in their structures like Sphinx or the pyramids. But when we talk about the philosophical or psychological aspect of the rituals followed by these civilisations, still there is a lacuna while associating any practise to logic. Numerous research is being conducted elucidating the logic behind these ritualistic practices, and many studies have shown the benefits of these practices. Similarly, the concept of public bath is a very common practice in Indian context. Its instances can be found as early as in Indus Valley Civilisations and also in current rustic scenario, where in people for their morning baths visit a community water body like river or wells. This paper exclusively talks about the psychological philosophy behind the public baths found in Indus Valley civilisations.

1.1 Indus Valley Civilisation

Indus Civilisation or Indus Valley Civilisation is the earliest civilisation found in Indian subcontinent. The civilisation is considered as an urban civilisation, owing to its planning and development. The Indus Valley civilisation is considered to be existing around 2500-1700 B.C., as per the findings of the nuclear dates. It is also suggested that the southern sites of the civilisation may have been in existence up to the 2nd millennium B.C.E The first site to be discovered pertaining to Indus Valley Civilisation was Harappa at Punjab region, and hence this civilisation is also referred to as Harappan Civilisation. The other sites discovered related to these civilisation are Sutkagen Kor (in Paksitan), Ropar or Rupar (in Punjab, India), Dholavira (in Gujarat, India), Lothal (in Gujarat, India), Rakhigarhi (in Haryana, India), Kalibangan (in Rajasthan, India), Balathal (in Rajasthan, India), Surkotada, Banawali, Alamgirpur, Mehrgarh, Mohenjodaro (in Pakistan). The discovery of these sites has established Indus Valley Civilisation as the most extensive civilisation among the 3 earliest civilisations (The Editors of Encyclopaedia Britannica, 2020) [1].

Mohenjo-daro present in modern Pakistan and situated on the banks of River Indus, is the site where in the great bath of Indus Valley Civilisation has been discovered. The prevalence of public baths implies the importance of ritualistic cleaning in their society. The notable part about these public baths is that they are surrounded by galleries and changing rooms. The Great Bath has no cracks or leaks in the structure and it reiterates the sturdy engineering capabilities of those people.

1.2 Psychological well-being

Psychological well-being has two parts. The first part refers to the level at which individual experience positive emotions and happiness. It is analogously used with the 
word subjective well-being (Diener, 2000) [2]. The other part refers to having a purpose and meaning in life. These two components influence a person's well-being.

Psychological well-being are of two types hedonic wellbeing and eudaimonic well-being. Hedonic well-being is defined as subjective well-being of happiness and has two components- affective state (related to feelings) and cognitive state (satisfaction with life). A person's wellbeing is high when a person has high positive affective sate and also he has a high level of satisfaction with life (Carruthers \& Hood, 2004) [3].

The other type of well-being known as eudaimonic well-being has six components that determine well-being (Ryff, 2004)[4]. The six components are autonomy, self acceptance, positive relationships, personal growth, environmental mastery and purpose in life. Autonomy refers to the person's ability to take be free and take decisions unaltered by social pressures. Self acceptance refers to the individuals ease and comfort related to oneself. A high level of positive relationships refers to the number of meaningful bonds a person has. Personal growth means the person's ability to grow, develop and move ahead in life after learning from mistakes. The fifth factor is environmental factor which refers to the individual's ability to utilise the environment or the surrounding factors for growth and development. The last factor refers to the person's goal orientation and meaning that an individual has attached to life.

\section{THE PSYCHOLOGICAL PHILOSOPHY BEHIND PUBLIC BATHS}

It has been proven that public baths were prevalent due to the tradition of ritualistic cleansing, but this paper presents a psychological perspective pertaining to these structures. It has been found that there is a significant correlation between body image and psychological well-being (Yazdani et al., 2018) [5]. The study found the correlation to be $\mathrm{r}=0.43$ at $\mathrm{P}<0.001$ and the main subjects for this research were people having morbid obesity. The result also stated a positive correlation body image and all subscales of psychological well-being except autonomy and purpose in life. Another study titled " The link between body dissatisfaction and self-esteem in adolescents: similarities across gender, age, weight status, race/ethnicity, and socioeconomic status" (van den Berg PA et al., 2010) [6] found that body dissatisfaction and self esteem had a strong correlation among adolescents of all age groups and was significant in both genders. Similarly a study titled " Body image satisfaction and depression in midlife women: the Study of Women's Health Across the Nation (SWAN)" (Jackson K.L. et al., 2015)[7] found that midlife women having poor body image are more susceptible to higher levels of depression.

As studies have suggested that people's perception of their body has an influence on their psychological wellbeing this paper presents the concept of public bath as to tackle the negative constrains pertaining to body image and thus resulting a better psychological well-being. The public baths were a concept where in people in groups engaged in bathing. This concept was a means to imbibe sociability in people but a new perspective pertaining to it could be that these baths were invented in order to develop a positive body image, resulting in a better psychological well-being. People when engaging in bathing, exposed their bodies to their acquaintances and this process acted as a cathartic method in order to instill self-esteem regarding their body image. When they exposed their bodies and in the process saw other bodies, this developed a sense of comfort and the fact that they solely weren't the only ones having these kind of body instilled a sense of oneness. Having a sense of belonging and comfort would have surely acted as a means of not fretting or not causing distress pertaining to their body. And thus, resulting in overall psychological well-being.

\section{RATIONALE OF THE STUDY}

This study could prove as a means to open up new ways to instill a sense of comfort pertaining to body image. And as a domino effect, this would act in a better well-being of the individuals. This study has a greater significance in now a days, where in people have distress or distorted body image. The social media being an active part of our lives has made a stereotypical body image collectively for people across the globe. This influence insidiously has created the perspective that deviance from that set image would be a cause of unhappiness and undesirability, resulting in bad well-being. If we could take the ancient concept and open up something similar to it, it would result in people accepting their bodies. Also, it would lower down the stress, unhappiness, anxiety and misery caused by the perception of body image.

\section{CONCLUSION}

Ancient texts like Vedas, Upanishads and all other texts are a Pandora of mammoth knowledge. There was psychology and philosophy related to all the traditions and rituals. This paper presents a supposed psychological philosophy behind the concept of public bath in Indus Valley Civilisations. Our ancestors were way ahead of us and they had figured out a euphoric lifestyle but it somehow lacked certain scientific findings to it. If we indulge in research finding the scientific reasons behind all the rituals and 
traditions of all cultures, it would surely open doorways to all the prevailing ills and issues in the globe.

\section{REFERENCES}

[1] Online article The Editors of Encyclopaedia Britannica (2020). Indus civilization. Encyclopædia Britannica. https://www.britannica.com/topic/Indus-civilization.

[2] Diener, E. (2000) Subjective wellbeing: The science of happiness and a proposal for a national index. American Psychologist, 55, 34-43.

[3] Carruthers, C. P., \& Hood, C. D. (2004). The power of the positive: Leisure and well-being. Therapeutic Recreation Journal, 38(2), 225-245.

[4] Ryff, C.D., Singer, B.H. and Love, G.D. (2004) Positive health: connecting wellbeing with biology. Philosophical Transactions of the Royal Society, 359, 1383-1394.

[5] Yazdani, N., Hosseini, V.S., Amini, M., Sobhani, Z., Sharif, F., Khazraei, H. (2018). Relationship between Body Image and Psychological Well-being in Patients with Morbid Obesity. International Journal of Community Based Nursing and Midwifery. 2018 Apr; 6(2): 175-184.

[6] Van den Berg PA, Mond J, Eisenberg M, Ackard D, Neumark-Sztainer D. (2010). The link between body dissatisfaction and self-esteem in adolescents: similarities across gender, age, weight status, race/ethnicity, and socioeconomic status. Journal of Adolescent Health. 2010 Sep;47(3):290-6.

[7] Jackson KL, Janssen I, Appelhans BM, et al. Body image satisfaction and depression in midlife women: the Study of Women's Health Across the Nation (SWAN). Archives of Women's Mental Health. 2014;17:177-87. 